\title{
Effects of dietary tryptophan and stocking density on the performance, meat quality, and metabolic status of broilers
}

\author{
Bo Wang, Zhizhi Min, Jianmin Yuan*, Bingkun Zhang and Yuming Guo
}

\begin{abstract}
Background: Highly automated cage-rearing systems are becoming increasingly popular in China. However, a high stocking density can cause oxidative stress and decrease broiler performance. The tryptophan (TRP) derivative 5-hydroxytryptophan (5-HT) has been shown to preserve membrane fluidity in birds suffering from oxidative stress. Therefore, this experiment was conducted to determine the effects of dietary TRP supplementation on performance, breast meat quality and oxidative stress in broilers reared in cages with a high or low stocking density.

Methods: Female Arbor Acres broilers (25-d-old, $n=144$ ) were randomly allocated to 1 of 4 treatments. The birds were fed a diet based on corn, soybean meal, cottonseed meal and corn gluten meal containing either 0.18 or $0.27 \%$ TRP and were housed with stocking densities of 11 or 15.4 birds $/ \mathrm{m}^{2}$ in a $2 \times 2$ factorial experiment. Broiler performance was evaluated from d 25 to 42 . Eight birds from each treatment were slaughtered on $\mathrm{d} 42$ and plasma and breast muscle samples were collected to measure biochemical indices.

Results: A higher stocking density tended to be associated with reduced weight gain $(P<0.10)$, and significantly increased plasma glutamic-pyruvic transaminase (GPT) activity $(P<0.001)$. Increased dietary TRP significantly reduced the activities of lactic dehydrogenase and GPT while increasing total cholesterol in the plasma $(P<0.01)$, reducing drip loss of breast muscle $(P<0.10)$ and improving feed efficiency $(P<0.10)$.

Conclusions: An increase in dietary TRP, 1.5-fold higher than the standard supplementation level, can alleviate oxidative stress as well as improve welfare and feed efficiency in broilers reared in cages with a high stocking density.
\end{abstract}

Keywords: Broiler, Meat quality, Performance, Stocking density, Tryptophan

\section{Background}

Increased attention is being paid to animal welfare and meat quality, factors that are strongly affected by stocking density [1]. A low stocking density is thought to be associated with high product quality, although it produces less meat and can therefore result in economic losses [1]. In contrast, a high stocking density can increase the quantity of broiler meat produced per unit area [2]. However, previous studies have shown that high stocking densities affect the amount of time broilers spend walking [3], decrease locomotor activity $[4,5]$, as well as increase the temperature, moisture, and ammonia concentrations in the chicken house, and cause leg and hock problems [6-8].

\footnotetext{
* Correspondence: yuanjm@cau.edu.cn

State Key Laboratory of Animal Nutrition, College of Animal Science and Technology, China Agricultural University, Beijing 100193, China
}

In addition, a high stocking density can increase disturbances [5] and conflicts between birds [9], and lead to apparent fearfulness $[8,10]$. Other problems associated with a high stocking density include increased heterophil: lymphocyte ratios [11], and increased plasma concentrations of glutathione peroxidase, leading to oxidative stress $[4,8,12]$. Thus, high stocking densities result in reduced growth, impaired feed efficiency, and poor quality of life for broilers $[4,13]$.

Tryptophan (TRP), the rate-limiting substrate of 5hydroxytryptamine (5-HT), is synthesized in the brain and competes with large neutral amino acids (LNAA) to cross the blood-brain barrier [14]. TRP supplementation significantly increased 5-HT turnover in the hippocampus and archistriatum and tended to do the same in the remainder of the forebrain [14]. Previous studies have shown 
that birds fed low-TRP diets exhibited abnormal behavior and signs of stress [15]. An increase in dietary TRP has been shown to reduce aggression, and alleviate stress in livestock and poultry $[16,17]$, reduce feather-pecking behavior and reduce hysteria in layers [18].

Excessive TRP reduced weight gain in weaned piglets [19] and rats [20]. However, no studies have investigated the effects of stocking density in relation to different concentrations of dietary TRP especially in broilers raised using cage rearing systems. Multi-storey cages or highly automated cage-rearing systems are becoming increasingly popular in China and other countries because they enable convenient management and removal of excreta and minimize bird contact with wastes, which reduces ammonia concentrations and improves chicken welfare. However, whether TRP supplementation can reduce stress and improve the welfare of broilers and quality of meat produced under high stocking densities is unknown. In this study, the effect of TRP supplementation on performance, breast meat quality, and the oxidative stress status of broilers reared in cages under high stocking density was investigated.

\section{Materials and methods}

\section{Bird management}

This protocol used in this study was approved and conducted in accordance with the guidelines of the Animal Ethics Committee of China Agricultural University (Beijing, China). Day-old female broiler chicks (Arbor Acres Plus), obtained from a commercial hatchery (Aviagen Group, Beijing, China), were raised in the middle floor of a 3 tier set of overlap cages. Individual cages were $70 \mathrm{~cm}$ long $\times$ $65 \mathrm{~cm}$ wide $\times 38 \mathrm{~cm}$ tall, and contained two nipple drinkers. A galvanized iron trough, hanging outside of the cage, was used to feed the broilers. Excreta was collected in trays under each cage, and was removed every 2 or $3 \mathrm{~d}$ to decrease ammonia concentrations in the broiler house.

Broilers were raised according to the Arbor Acres Broiler Management Guide (Aviagen Group, Beijing, China). The temperature was maintained at $34^{\circ} \mathrm{C}$ on day 1 , and was gradually reduced to $22^{\circ} \mathrm{C}$ by day 21 . Feed was offered ad libitum and water was freely available at all times. The relative humidity was maintained at $40-$ $65 \%$. The experiment was performed during winter and open windows were used to achieve cross-ventilation.

\section{Experimental design and diets}

The trial used a $2 \times 2$ factorial arrangement, involving 2 stocking densities and 2 concentrations of TRP. The normal stocking density was 5 birds/cage $\left(11 \mathrm{birds} / \mathrm{m}^{2}\right)$, and the high stocking density was 7 birds/cage (15.4 birds $/ \mathrm{m}^{2}$ ), according to Sørensen et al. [21]. The normal TRP concentration was defined as $0.18 \%$, on the basis of NRC (1994) nutritional requirements for broilers [22], and the high TRP concentration was $0.27 \%$ (1.5-fold higher than the normal concentration). Since the effects of stocking density occur primarily during the growing period [6], the experiment commenced when the broilers were 25 days of age. From days 1 to 24, the birds were fed a commercially prepared mash diet. On day 25 , the birds were individually weighed, and 144 birds with similar body weights, were randomly assigned to 24 cages. The difference in the average body weight among the cages was $<25 \mathrm{~g}$. From days 25 to 42 , birds were fed the experimental diets in mash form (Table 1).

\section{Measurements \\ Broiler performance}

From days 25 to 42, mortality, culling and feed intake were recorded daily for each pen. On day 42 , BW was recorded on a per cage basis to calculate the final BW and BW gain. Daily feed intake and feed efficiency were corrected for mortality.

\section{Metabolic status}

On day 42, blood samples were collected into heparinized tubes from the wing vein of 8 birds per treatment. The samples were centrifuged for $10 \mathrm{~min}$ at $3,000 \times g$, and plasma was collected and frozen at $-40^{\circ} \mathrm{C}$ for subsequent analysis of lactic dehydrogenase (LDH), glutamic-pyruvic transaminase (GPT), glutamic-oxalacetic transaminase (GOT), glucose (GLU), triglyceride (TG), and total cholesterol (TC). The analyses were performed using commercial analytical kits according to the manufacturer's recommendations (Jian Cheng Bioengineering Institute, Nanjing, China).

\section{Breast meat quality}

On day 42,8 birds closest to the average BW for each treatment were slaughtered. The left breast muscle was dissected, and breast muscle yield (without bone or skin) was measured as the ratio of 2 times the Pectoralis major and Pectoralis minor muscle mass to the final $\mathrm{BW}$ of the bird. The $\mathrm{pH}_{45}$ min post-mortem $\left(\mathrm{pH}_{45}\right)$ was measured using a TESTO $205 \mathrm{pH}$ meter (Testo Limited, Alton, Hampshire, UK) by inserting the electrode into three different points of the right section of the Pectoralis muscle and the average values were used for statistical analysis. Crude fat was measured by ether extraction of a 20-g sample of breast meat. An additional $20 \mathrm{~g}$ sample was placed in a polyethylene bag and drip loss was determined after $2 \mathrm{~d}$ of storage at $4^{\circ} \mathrm{C}$ [23].

\section{Statistical analysis}

The data was analyzed to assess the interactive effects of stocking density and TRP concentrations using the General Linear Model (GLM) of SPSS 15.0 [24]. Percentage 
Table 1 Composition and nutrient level of diets (air-dry basis)

\begin{tabular}{|c|c|c|}
\hline Item & $0.18 \%$ TRP & $0.27 \%$ TRP \\
\hline \multicolumn{3}{|l|}{ Ingredients, \% } \\
\hline Corn & 64.64 & 64.54 \\
\hline Soybean meal & 16.12 & 16.12 \\
\hline Cottonseed meal & 6.00 & 6.00 \\
\hline Corn gluten meal & 6.00 & 6.00 \\
\hline Soybean oil & 3.23 & 3.23 \\
\hline Limestone & 1.15 & 1.15 \\
\hline Dicalcium phosphate & 1.56 & 1.56 \\
\hline $\mathrm{NaCl}$ & 0.35 & 0.35 \\
\hline Vitamin premix ${ }^{1}$ & 0.02 & 0.02 \\
\hline Trace mineral premix ${ }^{2}$ & 0.20 & 0.20 \\
\hline DL-Met (98\%) & 0.04 & 0.04 \\
\hline L-Lys· HCl (78\%) & 0.40 & 0.40 \\
\hline L-Thr & 0.06 & 0.06 \\
\hline Choline chloride (50\%) & 0.16 & 0.16 \\
\hline L-Trp (98\%) & 0.01 & 0.10 \\
\hline Nutrient levels & 0.06 & 0.06 \\
\hline \multicolumn{3}{|l|}{ AME, Mcal/kg } \\
\hline Crude protein,\% & 3.10 & 3.10 \\
\hline Calcium, \% & 19.00 & 19.00 \\
\hline Available phosphorus, \% & 0.88 & 0.88 \\
\hline Nutrient levels & 0.40 & 0.40 \\
\hline \multicolumn{3}{|l|}{ Amino acid content } \\
\hline Lys, \% & 1.00 & 1.00 \\
\hline Met, \% & 0.38 & 0.38 \\
\hline Thr, \% & 0.64 & 0.64 \\
\hline Trp, \% & 0.18 & 0.27 \\
\hline
\end{tabular}

${ }^{1}$ The vitamin premix provided the following per kilogram of diet: vitamin $\mathrm{A}$, $10,000 \mathrm{IU}$; vitamin $\mathrm{D}_{3}, 2,400 \mathrm{IU}$; vitamin $\mathrm{E}, 20 \mathrm{IU}$; vitamin $\mathrm{K}_{3}, 2.00 \mathrm{mg}$; thiamin $2.00 \mathrm{mg}$; riboflavin, $6.40 \mathrm{mg}$; pyridoxin, $3.00 \mathrm{mg}$; $\mathrm{VB}_{12}, 0.02 \mathrm{mg}$; folic acid, $1.00 \mathrm{mg}$; pantothenic acid, $10.00 \mathrm{mg}$; nicotinic acid, $30.00 \mathrm{mg}$; biotin, $0.10 \mathrm{mg}$. ${ }^{2}$ The mineral premix provided the following per kg of diet: $\mathrm{Cu}, 8 \mathrm{mg}$; $\mathrm{Fe}$, $80 \mathrm{mg}$; Zn, $60 \mathrm{mg}$; Mn, 100 mg; l, $0.35 \mathrm{mg}$.

data was converted to degrees before Analysis of Variance was conducted and was subsequently back-transformed to generate an estimate of the standard error of the mean (SEM). Significance was set at $P<0.05$, and trends were recognized at $P<0.10$.

\section{Results}

\section{Performance}

Only one bird died during the experiment and as a result, mortality is not shown in the tables. There were no significant differences in the initial bodyweight among the experimental groups. However, increased stocking density tended to reduce the final BW and bodyweight gain $(P<0.10) \quad$ (Table 2$)$. There were no significant differences in feed efficiency or feed intake. The addition of dietary TRP tended to decrease feed efficiency $(P<$ $0.10)$ but had no effect on BW gain or feed intake. There were no significant interactions between dietary TRP concentrations and stocking density on the final BW, BW gain, or feed intake. However, high stocking density in combination with increased TRP supplementation significantly lowered feed efficiency compared with a high stocking density with normal TRP supplementation $(P<0.05)$, while a lower stocking density in combination with increased TRP supplementation did not significantly affect feed efficiency.

\section{Breast meat quality}

Increased stocking density had no significant effect on breast muscle yield, fat content, $\mathrm{pH}_{45}$, or drip loss (Table 3). Increased TRP concentration tended to reduce drip loss in the breast muscle of broilers $(P<0.10)$. There was no influence of TRP concentration on breast muscle yield, breast fat content, or $\mathrm{pH}_{45}$. Interactions between TRP concentration and stocking density were not significant for fat content, $\mathrm{pH}_{45}$, or drip loss. However, the high stocking density in combination with the low level of TRP supplementation tended to produce significantly higher breast muscle yield compared with the other treatments.

\section{Metabolic status}

A high stocking density tended to increase plasma GLU $(P<0.10)$, and significantly increased plasma GPT activity $(P<0.001)$. There were no significant differences in the activity of LDH and GOT or in the plasma levels of TG and TC.

Increased dietary TRP significantly increased plasma TC $(P<0.05)$, and decreased LDH and GPT activities $(P<0.01)$. There were no significant differences in GOT activity or in GLU and TG levels between the TRP treatments. Significant interactive effects were observed between TRP concentration and stocking density for plasma GLU $(P<0.01)$, LDH activity $(P<0.05)$, and GPT activity $(P<0.001)$. A high stocking density in combination with increased dietary TRP significantly increased GLU content compared with the other treatments and significantly decreased GPT activity compared with the normal TRP treatment with a high stocking density, although the level did not differ significantly from the low stocking density treatments. A high stocking density in combination with increased TRP supplementation significantly decreased LDH activity compared with the low-TRP treatment, but showed no significant differences from the low stocking density treatment. 
Table 2 Effects of stocking density and tryptophan (TRP) level on broiler performance ${ }^{1}$

\begin{tabular}{|c|c|c|c|c|c|c|}
\hline Stocking density, birds $/ \mathrm{m}^{2}$ & Tryptophan Level, \% & Initial Bodyweight, g & Final Bodyweight, $\mathrm{g}$ & $\begin{array}{l}\text { Daily bodyweight } \\
\text { Gain, } g\end{array}$ & $\begin{array}{c}\text { Feed Intake, } \\
\text { g/d }\end{array}$ & $\begin{array}{c}\text { Feed } \\
\text { efficiency }\end{array}$ \\
\hline \multicolumn{7}{|c|}{ Stocking density $\times$ tryptophan level } \\
\hline 11.0 & 0.18 & 778 & 1,960 & 69.53 & 127.2 & $1.83^{b}$ \\
\hline 11.0 & 0.27 & 780 & 1,961 & 69.47 & 126.5 & $1.82^{b}$ \\
\hline 15.4 & 0.18 & 781 & 1,887 & 65.00 & 123.5 & $1.90^{\mathrm{a}}$ \\
\hline 15.4 & 0.27 & 781 & 1,939 & 68.06 & 123.2 & $1.81^{\mathrm{b}}$ \\
\hline SEM & & 5.6 & 76.2 & 4.250 & 6.30 & 0.059 \\
\hline \multicolumn{7}{|l|}{ Stocking density } \\
\hline 11.0 & & 779 & 1,963 & 69.65 & 126.8 & 1.82 \\
\hline 15.4 & & 781 & 1,913 & 66.59 & 123.4 & 1.85 \\
\hline SEM & & 1.1 & 16.4 & 0.900 & 1.28 & 0.012 \\
\hline \multicolumn{7}{|l|}{ Tryptophan level } \\
\hline $0.18 \%$ & & 780 & 1,924 & 67.24 & 125.3 & 1.86 \\
\hline $0.27 \%$ & & 782 & 1,950 & 68.76 & 124.9 & 1.82 \\
\hline SEM & & 1.1 & 15.5 & 0.057 & 1.28 & 0.015 \\
\hline \multicolumn{7}{|l|}{$P$-values } \\
\hline Stocking density & & 0.351 & 0.084 & 0.089 & 0.214 & 0.144 \\
\hline TRP level & & 0.891 & 0.564 & 0.509 & 0.851 & 0.052 \\
\hline Density $\times$ TRP & & 0.659 & 0.265 & 0.375 & 0.938 & 0.045 \\
\hline
\end{tabular}

${ }^{1}$ Each mean represents 6 replicates for each treatment with each replicate containing $5\left(11.0 \mathrm{birds} / \mathrm{m}^{2}\right)$ or 7 birds $\left(15.4 \mathrm{birds} / \mathrm{m}^{2}\right)$.

${ }^{a, b}$ Means in the same row with different superscripts are significantly different $(P<0.05)$.

\section{Discussion}

In this study, increased stocking density tended to reduce weight gain of broilers (Table 2), a finding that is consistent with previous studies that demonstrated that a high stocking density is associated with decreased BW [4], especially during the growing period [7]. However, Estevez [25] suggested that the recommended stocking density could be increased to approximately $18 \mathrm{birds} / \mathrm{m}^{2}$ without any major adverse effects on the final BW. Ekstrand and Carpenter [26] proposed that the response to changes in stocking density depended on environmental variables. Differences in the environment provided to chickens by poultry producers might have greater effects on welfare than stocking density [27].

Clements [28] reviewed numerous articles on stocking density and animal welfare and concluded that there was no significant relationship between stocking density and behavior, leg problems, or skin damage. Under deep litter conditions, growth rate was significantly reduced when stocking density exceeded approximately $30 \mathrm{~kg} / \mathrm{m}^{2}$ live weight [7]. However, the effects of litter and stocking density on growth were attenuated when ventilation was increased or when broilers were raised with perforated flooring.

Increased litter temperature has been identified as a causal factor for reduced growth rate [29]. High stocking densities might contribute to reduced broiler performance because of high temperatures and reduced airflow at the bird level [26]. The reduction in BW gain at a stocking density of $15.4 \mathrm{birds} / \mathrm{m}^{2} \mathrm{com}-$ pared with that at a stocking density of 11 birds $/ \mathrm{m}^{2}$ might be related to the cage environment (e.g., air flow, temperature, and cage area). Cage area might affect broiler performance, which also affects locomotor activity $[4,5]$. Suitable stocking density when birds are raised in cages might differ from the stocking density required when birds are raised with open litter floor or perforated flooring. The suitable stocking density of broilers raised in 3-tier-overlap cages would be $<15.4$ birds $/ \mathrm{m}^{2}$ if simple cross ventilation were used by opening windows during the winter.

Increasing the stocking density of female birds from 11 to $15.6 \mathrm{birds} / \mathrm{m}^{2}$ did not affect breast meat yield (Table 3), which is in agreement with the findings of Moreira et al. [30] who showed that densities between 10 and 16 birds $/ \mathrm{m}^{2}$ did not affect broiler meat quality characteristics (cooking loss, shear force, and $\mathrm{pH}$ ) in Ross 308, Cobb 500, and Hybro PG commercial strains. Thomas et al. [10] also showed that stocking densities of 10,15 , and 20 birds $/ \mathrm{m}^{2}$ had no influence on carcass characteristics. However, Rilgili and Hess [31] found that increased stocking density could significantly reduce 
Table 3 Effects of stocking density and tryptophan level on breast meat quality of broilers ${ }^{1}$

\begin{tabular}{|c|c|c|c|c|c|c|}
\hline \multirow{2}{*}{$\begin{array}{l}\text { Stocking density, } \\
\text { birds } / \mathrm{m}^{2}\end{array}$} & \multirow{2}{*}{$\begin{array}{c}\text { Tryptophan } \\
\text { level, } \%\end{array}$} & \multirow{2}{*}{$\begin{array}{c}\text { Body } \\
\text { weight, } \\
\text { kg }\end{array}$} & \multicolumn{4}{|c|}{ Breast muscle } \\
\hline & & & Yield, \% & Fat content, $\%$ & $\mathrm{pH}_{45}^{2}$ & Drip loss, $\%$ \\
\hline \multicolumn{7}{|c|}{ Stocking density $\times$ tryptophan level } \\
\hline 11.0 & 0.18 & 1.87 & 14.25 & 0.79 & 6.07 & 9.17 \\
\hline 11.0 & 0.27 & 1.98 & 14.82 & 0.69 & 6.11 & 8.50 \\
\hline 15.4 & 0.18 & 1.87 & 15.45 & 0.66 & 6.16 & 11.60 \\
\hline 15.4 & 0.27 & 1.82 & 14.43 & 0.67 & 6.13 & 8.16 \\
\hline SEM & & 0.228 & 1.083 & 0.121 & 0.195 & 2.502 \\
\hline \multicolumn{7}{|l|}{ Stocking density } \\
\hline 11.0 & & 1.93 & 14.54 & 0.74 & 6.09 & 8.84 \\
\hline 15.4 & & 1.85 & 14.94 & 0.66 & 6.14 & 9.63 \\
\hline SEM & & 0.046 & 0.173 & 0.025 & 0.040 & 0.511 \\
\hline \multicolumn{7}{|l|}{ Tryptophan level } \\
\hline $0.18 \%$ & & 1.87 & 14.85 & 0.73 & 6.11 & 10.14 \\
\hline $0.27 \%$ & & 1.90 & 14.62 & 0.68 & 6.12 & 8.33 \\
\hline SEM & & 0.046 & 0.173 & 0.025 & 0.040 & 0.511 \\
\hline \multicolumn{7}{|l|}{$P$ Value } \\
\hline Stocking density & & 0.405 & 0.356 & 0.130 & 0.533 & 0.425 \\
\hline TRP level & & 0.745 & 0.599 & 0.351 & 0.907 & 0.077 \\
\hline Density $\times$ TRP & & 0.405 & 0.077 & 0.302 & 0.710 & 0.258 \\
\hline
\end{tabular}

${ }^{1}$ Each mean represents 8 birds for each treatment.

${ }^{2}$ Note: $\mathrm{pH}_{45}$ represents $\mathrm{pH}$ value for breast meat $45 \mathrm{~min}$ after slaughter.

carcass quality and breast meat yield in fast-growing male birds, whereas slow-growing female birds were not affected. Simitzis et al. [4] showed that high stocking density decreased intramuscular breast fat.

The effects of stocking density on meat quality might be related to growth rate. Puron et al. [2], showed that similar masses of meat were produced when housing density exceeded 17 male or 19 female birds $/ \mathrm{m}^{2}$ which was close to the densities recommended to minimize the adverse effects of crowding on broiler welfare. The stocking densities of female broilers in the current study (11 and 15.4 birds $/ \mathrm{m}^{2}$ ) were lower than those used by Puron et al. [2], and slow growing female broilers were used in the current study, similar to the experiment of Rilgili and Hess [31] which might explain the lack of significant differences in breast meat quality between the 2 stocking densities.

Simsek et al. [12] compared stocking densities of 6 and 13 birds $/ \mathrm{m}^{2}$ and found that a high stocking density decreased feeding time and caused oxidative stress. Simitzis et al. [4] showed that a high stocking density was associated with decreased locomotor activity and increased indicators of physiological (heterophil: lymphocyte ratio and bursa weight), and oxidative stress. However, other researchers have shown that stocking density did not affect the major physiological stress indicators, including plasma glucose and cholesterol [32] and fecal corticosterone concentrations $[8,27]$. In this study, a high stocking density did not influence the levels of TG or TC or the activities of LDH and GOT in the plasma, which is in agreement with previous studies $[7,33]$. However, an increased stocking density significantly increased GPT activity in the plasma.

Serum GPT and GOT are commonly measured clinically as a part of diagnostic liver-function tests to determine liver health. Levels of serum GPT and GOT generally increase with muscle or liver damage [34]. The significantly increased GPT activity indicates that a high stocking density might cause oxidative lesions, which is in agreement with the findings of Simsek et al. [14]. However, whether or not increased stocking density causes oxidative stress with no change in LDH activity related to the stress level needs further research.

Previous studies have shown that the TRP derivative 5-hydroxytryptophan could help preserve membrane fluidity in animals experiencing oxidative stress [35]. Another important TRP derivative, melatonin, was found to have anti-oxidative properties [36,37]. In the current study, increased dietary TRP significantly decreased the TC and the activities of LDH and GPT in plasma 
Table 4 Effects of stocking density and tryptophan (TRP) level on plasma parameters of broilers ${ }^{1}$

\begin{tabular}{|c|c|c|c|c|c|c|c|}
\hline Stocking density, birds $/ \mathrm{m}^{2}$ & Tryptophan Concentration, \% & $\mathrm{LDH}^{2}, \mathrm{U} / \mathrm{L}$ & $\mathrm{GLU}, \mathrm{mg} / \mathrm{dL}$ & $\mathrm{TG}, \mathrm{mg} / \mathrm{dL}$ & $\mathrm{TC}, \mathrm{mg} / \mathrm{dL}$ & GPT, U/L & GOT, U/L \\
\hline \multicolumn{8}{|c|}{ Stocking density $\times$ tryptophan level } \\
\hline 11.0 & 0.18 & $24,219^{a b}$ & $239.1^{b}$ & 39.49 & 106.1 & $2.88^{b}$ & 32.92 \\
\hline 11.0 & 0.27 & $22,317^{b}$ & $228.2^{b}$ & 51.48 & 121.2 & $3.83^{b}$ & 31.95 \\
\hline 15.4 & 0.18 & $28,028^{\mathrm{a}}$ & $232.6^{b}$ & 48.30 & 104.8 & $9.10^{\mathrm{a}}$ & 32.60 \\
\hline 15.4 & 0.27 & $19,695^{\mathrm{b}}$ & $256.9^{\mathrm{a}}$ & 58.97 & 121.2 & $5.05^{b}$ & 32.33 \\
\hline SEM & & $5,106.0$ & 16.66 & 17.956 & 16.67 & 2.595 & 4.575 \\
\hline \multicolumn{8}{|l|}{ Stocking density } \\
\hline 11.0 & & 23,268 & 233.6 & 45.49 & 113.6 & 3.36 & 32.43 \\
\hline 15.4 & & 23,861 & 244.8 & 53.63 & 113.0 & 7.08 & 32.47 \\
\hline SEM & & $1,042.3$ & 3.40 & 3.665 & 3.40 & 0.529 & 0.934 \\
\hline \multicolumn{8}{|l|}{ TRP level } \\
\hline $0.18 \%$ & & 26,123 & 235.9 & 43.89 & 105.4 & 5.99 & 32.76 \\
\hline $0.27 \%$ & & 21,006 & 242.5 & 55.23 & 121.2 & 4.44 & 32.14 \\
\hline SEM & & $1,042.3$ & 3.40 & 3.665 & 3.40 & 0.529 & 0.934 \\
\hline \multicolumn{8}{|l|}{$P$ value } \\
\hline Stocking density & & 0.742 & 0.053 & 0.272 & 0.925 & $<0.001$ & 0.987 \\
\hline TRP level & & 0.009 & 0.232 & 0.132 & 0.023 & 0.001 & 0.761 \\
\hline Density $\times$ TRP & & 0.024 & 0.004 & 0.928 & 0.925 & $<0.001$ & 0.863 \\
\hline
\end{tabular}

(Table 4). Increased plasma GPT activity under a high stocking density was moderated by the increase in dietary TRP concentration, suggesting that increased dietary TRP could help prevent liver injury resulting from a high stocking density.

The cytoplasmic enzyme LDH is widely used as a marker of organ or tissue lesions in toxicology and clinical chemistry. LDH is generally associated with cellular metabolic activity, which is inhibited or elevated under oxidative stress [38]. The significant decrease in LDH activity observed in the present study with dietary supplementation of $0.27 \%$ of TRP under the high stocking density conditions, indicates that TRP level can reduce the stress caused by a high stocking density.

Corzo et al. [15], showed that supplemental TRP increased plasma glucose in a linear manner, whereas other physiological stress variables were unaffected by dietary TRP. Plasma glucose exhibited a linear response to TRP supplementation, most likely due to adrenergicdriven glycolytic factors, unlike the gluconeogenic events associated with physiological stress [34].

Previous study showed that a high stocking density increased plasma concentrations of glutathione peroxidase, leading to oxidative stress $[4,8,12]$. TRP treatment significantly increased the TRP/LNAA ratio in the plasma of the chicks. Furthermore, TRP treatment increased baseline and stress-induced levels of plasma corticosterone, which inhibits glycolysis [16]. Supplementation with the high concentration of TRP significantly increased TC levels compared with low TRP concentrations (Table 4), which also indicates that increased TRP could help alleviate oxidative stress. This might explain why high concentrations of TRP tended to alter feed efficiency. This indicates that increased TRP concentration could help to improve feed efficiency under high stocking densities.

Drip loss can indicate quality deviations associated with the rate and extent of postmortem glycolysis in muscle tissue. The volume of drip loss is related to the lipid peroxide content in muscle [39]. Our finding that high TRP supplementation reduced drip loss under a high stocking density indicates that administration of TRP could lead to a reduction of lipid peroxide and glycolysis values caused by stress due to a high stocking density, thus improving meat quality.

In conclusion, increasing the stocking density from 11 to 15.4 birds $/ \mathrm{m}^{2}$ caused oxidative stress in broilers and tended to reduce their performance. Supplementation with TRP at concentrations 1.5-fold higher than the standard dose commonly supplemented could alleviative oxidative stress caused by stocking density and could improve broiler welfare, meat quality, and feed efficiency. 


\section{Abbreviations}

BW: Body weight; GLU: Glucose; GOT: Glutamic-oxalacetic transaminase; GPT: Glutamic-pyruvic transaminase; LDH: Lactic dehydrogenase; LNAA: Large neutral amino acids; TC: Total cholesterol content; TG: Triglyceride; TRP: Tryptophan

\section{Competing interests}

The authors declare that they have no competing interests.

\section{Authors' contributions}

BW and ZM carried out the experiments, JY wrote the manuscript, BZ, and YG participated in the design of the study. All authors read and approved the final manuscript.

\section{Acknowledgments}

This research was supported by the System for Poultry Production Technology, Beijing Innovation Research Team of Modern Agriculture (CARSPSTP), and the National Key Technology R\&D Program of China during the $12^{\text {th }}$ five-year plan (2012BAD39B04).

Received: 20 June 2014 Accepted: 22 September 2014 Published: 26 September 2014

\section{References}

1. Vanhonacker F, Verbeke W, Van Poucke E, Buijs S, Tuyttens FAM: Societal concern related to stocking density, pen size and group size in farma animal production. Livestock Sci 2008, 113:123-132.

2. Puron D, Santamaria R, Segura JC, Alamilla JL: Broiler performance at different stocking densities. J Appl Poult Res 1995, 4:55-60.

3. Febrer $K$, Jones TA, Donnelly CA, Dawkins MS: Forced to crowd or choosing to cluster? Spatial distribution indicates social attraction in broiler chickens. Anim Behav 2006, 72:1291-1300.

4. Simitzis PE, Kalogeraki E, Goliomytis M, Charismiadou MA, Triantaphyllopoulos K, Ayoutanti A, Niforou K, Hager-Theodorides AL, Deligeorgis SG: Impact of stocking density on broiler growth performance, meat characteristics, behavioural components and indicators of physiological and oxidative stress. Br Poult Sci 2012, 53:721-730.

5. Ventura BA, Siewerdt F, Estevez I: Access to barrier perches improves behavior repertoire in broilers. PLoS One 2012, 7:e29826. doi:10.1371/ journal.pone.0029826. Epub 2012 Jan 27.

6. Dozier WA 3rd, Thaxton JP, Branton SL, Morgan GW, Miles DM, Roush WB, Lott BD, Vizzier-Thaxton Y: Stocking density effects on growth performance and processing yields of heavy broilers. Poult Sci 2005, 84:1332-1338

7. Dozier WA 3rd, Thaxton JP, Purswell JL, Olanrewaju HA, Branton SL, Roush WB: Stocking density effects on male broilers grown to 1.8 kilograms of body weight. Poult Sci 2006, 85:344-351.

8. Buijs S, Keeling L, Rettenbacher S, Van Poucke E, Tuyttens FAM: Stocking density effects on broiler welfare: Identifying sensitive ranges for different indicators. Poult Sci 2009, 88:1536-1543.

9. Yakubu A, Gwaska JA, Salako AE: Strain and placement density effects on welfare, haematological and serum biochemical indices of broilers in north central Nigeria. Acta Agric Slovenica 2009, 94:153-158.

10. Thomas DG, Ravindran V. Thomas DV, Camden BJ, Cottam YH, Morel PC, Cook CJ: Influence of stocking density on the performance, carcass characteristics and selected welfare indicators of broiler chickens. $N Z$ Vet J 2004, 52:76-81.

11. Puvadolpirod S, Thaxton JP: Model of physiological stress in chickens 1. Response parameters. Poult Sci 2000, 79:363-369.

12. Simsek UG, Dalkilıc B, Ciftci M, Yuce A: The influences of different stocking densities on some welfare indicators, lipid peroxidation (MDA) and antioxidant enzyme activities (GSH, GSH-Px, CAT) in broiler chickens. J Anim Vet Adv 2009, 8:1568-1572.

13. Cortamira NO, Seve B, Lebreton Y, Ganier P: Effect of dietary tryptophan on muscle, liver and whole-body protein-synthesis in weaned piglets - Rrelationship to plasma-insulin. Br J Nutr 1991, 66:423-435

14. Van Hierden YM, Koolhaas JM, Korte SM: Chronic increase of dietary I-tryptophan decreases gentle feather pecking behaviour. Appl Anim Behav Sci 2004, 89:71-84

15. Corzo A, Kidd MT, Thaxton JP, Kerr BJ: Dietary tryptophan effects on growth and stress responses of male broiler chicks. Br Poult Sci 2005 $46: 478-484$
16. Shea MM, Mench JA, Thomas OP: The effect of dietary tryptophan on aggressive behavior in developing and mature broiler breeder males. Poult Sci 1990, 69:1664-1669.

17. Mench JA: Research note: Feed restriction in broiler breeders causes a persistent elevation in corticosterone secretion that is modulated by dietary tryptophan. Poult Sci 1991, 70:2547-2550.

18. Laycock SR, Ball RO: Alleviation of hysteria in laying hens with dietary tryptophan. Can J Vet Res 1990, 54:291-295.

19. Edmonds MS, Baker DH: Methionine, tryptophan, threonine or leucine amino acid excesses for young pigs: Effects of excess. J Anim Sci 1987 64:1664-1671.

20. Gross B, Ronen N, Honigman S, Livne E: Tryptophan toxicity-time and dose response in rats. Adv Exp Med Biol 1999, 467:507-516.

21. Sørensen P, Su G, Kestin SC: Effects of age and stocking density on leg weakness in broiler chickens. Poult Sci 2000, 79:864-870

22. Council NR: Nutrient Requirement of Poultry. 9th edition. Washington, DC: National Academy Press; 1994.

23. Lundstrom K, Malmfors G: Variation in light scatter and water-holding capacity along the porcine longissimus doris muscle. Meat Sci 1985 15:203-214.

24. Spss 15.0 Command Syntax Reference. Chicago III: SPSS Inc; 2006

25. Estevez I: Density allowances for broilers: Where to set the limits? Poult Sci 2007, 86:1265-1272.

26. Ekstrand C, Carpenter TE: Temporal aspects of foot-pad dermatitis in Swedish broilers. Acta Vet Scand 1998, 39:229-236

27. Dawkins MS, Donnelly CA, Jones TA: Chicken welfare is influenced more by housing conditions than by stocking density. Nature 2004, 427:342-344.

28. Clements $\mathrm{M}$ : Is the poultry industry making the most of its data? Poult Int 2013, 52:6-12

29. Feddes JJR, Emmanuel EJ, Zuidhof MJ: Broiler performance, BW variance, feed and water intake, and carcass quality at different stocking densities. Poult Sci 2002, 81:774-779.

30. Moreira J, Mendes AA, Roca RO, Garcia EA, Naas IA, Garcia RG, Lima IC, Paz A: Effect of stocking density on performance, carcass yield and meat quality in broilers of different commercial strains. R Bras Zootec 2004, 33:1506-1519.

31. Rilgili SF, Hess JB: Placement density influences broiler carcass grade and meat yields. J Appl Poult Res 1995, 4:384-389.

32. Thaxton JP, Dozier WA 3rd, Branton SL, Morgan GW, Miles DW, Roush WB, Lott BD, Vizzier-Thaxton Y: Stocking density and physiological adaptive responses of broilers. Poult Sci 2006, 85:819-824.

33. Škrbić Z, Pavlovski Z, Lukić M, Perić L, Milošević N: The effect of stocking density on certain broiler welfare parameters. Biotechnol Anim Husbandry 2009, 25:11-21.

34. Özbey $\mathrm{O}$, Esen F: The effects of breeding system and stocking density on some blood parameters of rock partridges (Alectoris graeca). Poult Sci 2007, 86:420-422.

35. Reyes-Gonzales MC, Fuentes-Broto L, Martínez-Ballarín E, Miana-Mena FJ, Berzosa C, García-Gil FA, Aranda M, García JJ: Effects of tryptophan and 5-hydroxytryptophan on the hepatic cell membrane rigidity due to oxidative stress. J Membr Biol 2009, 231:93-101.

36. Ghosh G, De K, Maity S, Bandyopadhyay D, Bhattacharya S, Reiter RJ, Bandyopadhyay A: Melatonin protects against oxidative damage and restores expression of GLUT4 gene in the hyperthyroid rat heart. J Pineal Res 2007, 42:71-82.

37. Mollaoglu H, Topal T, Ozler M, Uysal B, Reiter RJ, Korkmaz A, Oter S: Antioxidant effects of melatonin in rats during chronic exposure to hyperbar. J Pineal Res 2007, 42:50-54.

38. Das PC, Ayyappan S, Das BK, Jena JK: Ni- trite toxicity in Indian major carps: Sublethal effect on selected enzymes in fingerlings of Catla catla Labeo rohita, and Cirrhi- nus mrigala. Comp Biochem Physiol C Toxicol Pharmacol 2004, 138:3-10.

39. Tavárez MA, Boler DD, Bess KN, Zhao J, Yan F, Dilger AC, Mckeith FK, Killefer $\mathrm{J}$ : Effect of antioxidant inclusion and oil quality on broiler performance, meat quality, and lipid oxidation. Poult Sci 2011, 90:922-930.

doi:10.1186/2049-1891-5-44

Cite this article as: Wang et al:: Effects of dietary tryptophan and stocking density on the performance, meat quality, and metabolic status of broilers. Journal of Animal Science and Biotechnology 2014 5:44. 